\title{
A Retrospective analysis on Oral Squamous Cell Carcinoma Patients Indicated for Chemotherapy
}

\author{
Harini $\mathbf{G}^{1}$, Kathiravan Selvarasu2* \\ ${ }^{1}$ Saveetha Dental College and Hospitals, Saveetha Institute of Technical and \\ Medical Sciences, Saveetha University, Chennai -600077, India \\ 2.Department of Oral and Maxillofacial Surgery, Saveetha Dental College \\ and Hospitals, Saveetha Institute of Technical and Medical Sciences, Saveetha \\ University, Chennai-600077, India \\ Corresponding author email: kathiravan.sdc@saveetha.com
}

\begin{abstract}
Neo adjuvant chemotherapy has been studied in oral cavity with the aim of improving locoregional control and overall survival rates as an organ preservation tool in the resettable cancers. It is usually given post operative to improve the quality of life and to increase the survival rates. This study was conducted by reviewing the records of patients visiting the Oral Oncology department in Saveetha Dental College and hospitals, between 1 st June 2019 -1 st April 2020. Among 57 carcinoma patients (maxillary, mandibular, buccal carcinoma) $16(28 \%)$ patients were treated with the chemotherapy post operatively. There was male predominance with 9 males $(57 \%)$ and 7 females (43\%) in this study. The mean age of the patient's undergoing chemotherapy was 40-50 years, ranging from 20 to 60 years of age. Among various sites of carcinoma patients subjected to chemotherapy, maxillary carcinoma accounted to 8 patients (50\%) mandibular carcinoma- 5 patients (31.25\%), buccal mucosa carcinoma- 3 patients (18.75\%) Chi-square test was done on association between gender and number of patients with carcinoma in different sites and found not statistically significant [chi square value- $0.2320, p$ value- $0.314(\mathrm{p}>0.05)$ ]. Chi-square test was done to find the association between age and type of carcinoma and was found to be statistically not significant [chi square value- $0.529, \mathrm{p}$ value- $0.612(\mathrm{p}>0.05)$ ]. From this study we can conclude that chemotherapy treatment was commonly undergone by men and patients in the 4th decade of life. Maxillary carcinoma patients underwent chemotherapy more commonly as compared to mandibular carcinoma patients or buccal carcinoma patients. Association between age and incidence of chemotherapy treatment, gender and incidence of chemotherapy treatment was found statistically not significant.
\end{abstract}

\section{KEY WORDS: CHEMOTHERAPY; BUCCAL CARCINOMA; ORAL SQUAMOUS CELL CARCINOMA; INCREASED SURVIVAL RATE.}

\section{INTRODUCTION}

Chemotherapy encompasses a wide variety of treatment which uses powerful chemicals to kill fast growing cells in the body. It is used to treat cancer cells that grow and multiply more rapidly than normal cells. Drugs used in chemotherapy affect quickly dividing cells by means of interfering with cell division. Though the cells widely

Biosc Biotech Res Comm P-ISSN: 0974-6455 E-ISSN: 2321-4007

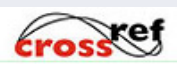

Identifiers and Pagination

Year: 2021 Vol: 14 No (10) Special Issue

Pages: $70-75$

This is an open access article under Creative

Commons License Attribn 4.0 Intl (CC-BY).

DOI: $h t t p: / / d x$.doi.org/10.21786/bbrc/14.10.12 vary in their susceptibility to these agents, generally these drugs are cytotoxic and thus it works against cancer cells. Chemotherapy treatment is generally given in cycles with each treatment followed by a rest period to allow body time to recover. Sometimes chemotherapy is also given along with radiation known as chemoradiation. The use of combined chemotherapy and radiation has been studied extensively for the treatment of locally advanced oral and other head and neck cancers, both as a means of organ preservation and as a primary therapy, even when organ preservation is not necessarily a goal. Notably, although oral cancers were well-represented in trials of adjuvant chemoradiation, they have typically been under-represented in trials of primary chemoradiation(Neville and Day, 2002; Kademani, 2007; Kalavrezos and Bhandari, 2010; Varghese et al., 2019; Muthukrishnan et al., 2020).
Article Information

Received: $15^{\text {th }}$ Aug 2021

Accepted after revision: $23^{\text {th }}$ Oct 2021 
Chemotherapeutic drugs are classified into five major categories based on the way the drugs affect cell chemistry. Drugs are classified into a specific category depending on what part of the cell cycle the drug interrupts. The categories are Alkylating Agent (Cyclophosphamide and Mechlorethamine, Cisplatin), Nitrosoureas (Carmustine, Lomustine), Antimetabolites (6-mercaptopurine and 5-fluorouracil), Antitumor Antibiotics (Doxorubicin and Mitomycin-C), Plant Alkaloids (Vincristine and Vinblastine.), and Steroid Hormones (Tamoxifen and Flutamide) of which commonly used ones are Carboplatin, 5-fluorouracil (5-FU), Paclitaxel (Taxol), Docetaxel (Taxotere), Hydroxyurea. Drug regimen is chosen depending on what type of cancer to be treated and which stage of the cell's life cycle the drugs affect (Nagesh Rao, 2017; Varghese et al., 2019; Muthukrishnan et al., 2020).

In the battle against cancer, one of the main multimodality methods used for reducing morbidity and mortality is surgical therapy in conjunction with radiation and chemotherapy. What makes chemotherapy very effective, is that it has the ability to treat widespread (metastatic) cancer, that is in more than one location in your body and thereby reducing the incidence of metastatic recurrence. When these three treatments are used in conjunction, their complimentary avenues of attacking the disease frequently offer the patient the best chance to reduce psychological anxiety as well physiological stress and beat cancer. Chemotherapy is advocated in certain benign lesions of the jaw which can sometimes cause significant erosion of bone leading to pathological bone fracture and proliferate into soft tissue areas mimicking oral soft tissue pathologies (Ma et al., 2013; Abhinav et al., 2019; Packiri, 2017; Kumar, 2017a; Packiri et al., 2017; Christabel et al., 2016; Jain et al., 2019; Samuel et al., 2020).

Previously our team has a rich experience in working on various research projects across multiple disciplines (Gheena and Ezhilarasan, 2019; Ke et al., 2019; Malli Sureshbabu et al., 2019; Mehta et al., 2019; Samuel et al., 2019; Sharma et al., 2019; Varghese et al., 2019; Venu et al., 2019; Vignesh et al., 2019; Jain et al., 2019; Jose et al., 2020; Krishnaswamy et al., 2020; Muthukrishnan et al., 2020; Samuel et al., 2020; Sathish and Karthick, 2020). Now the growing trend in this area motivated us to pursue this project.

\section{MATERIAL AND METHODS}

Subjects were the patients who visited Saveetha dental college and hospitals. They are grouped accordingly to the gender. This study was approved by the ethical committee for research at saveetha dental College. SDC/SIHEC/2020/ DIASDATA/0619-0320. Data according to the patient were collected by reviewing the case records of 86,000 overall patients in the lapse of 1 st june 2019 -1 st april 2020. The patients intra oral photos, history of presenting illness, systemic disease, treatment given were accessed.

Statistics Analysis: The data was tabulated and analysed using IBM SPSS version 2.0. Non-parametric data were analysed using descriptive statistics measuring percentage and frequency. The association between Incidence of Postoperative Chemotherapy in OSCC,age, types of carcinoma and gender was done with Pearson's Chi-square test

\section{Inclusion Criteria: Carcinoma including \\ - Maxilla \\ - Squamous cell carcinoma \\ - Adenoid cystic carcinoma \\ - Adenocarcinoma \\ - Mucoepidermoid carcinoma \\ - Malignant melanoma}

\section{Mandible}

- Squamous cell carcinoma

- Osteosarcoma

- Giant cell tumour

- Ewing tumour

- Multiple myeloma

\section{Exclusion Criteria}

- $\quad$ Physically challenged

- Patient under 18 years age

- Patient underwent radiotherapy

In regards to the site of the oral carcinoma, we adhered to the site of occurrence, gender, age group affected and the treatment modality used for management of oral squamous cell carcinoma in the post-surgical phase.

Figure 1: Figure shows Age wise distribution of patients who underwent chemotherapy. $X$ axis denotes age of patients and $Y$ axis denotes the number of the patients. 21-30 years(turquoise)-1 patient;31-40 years (light green)-6 patients;41-50 years (pale pink)-7 patients; $51-60$ years(sandal)-2 patients. Age distribution was found and 4150 years age group was commonly treated by chemotherapy. SPSS analysis was used.

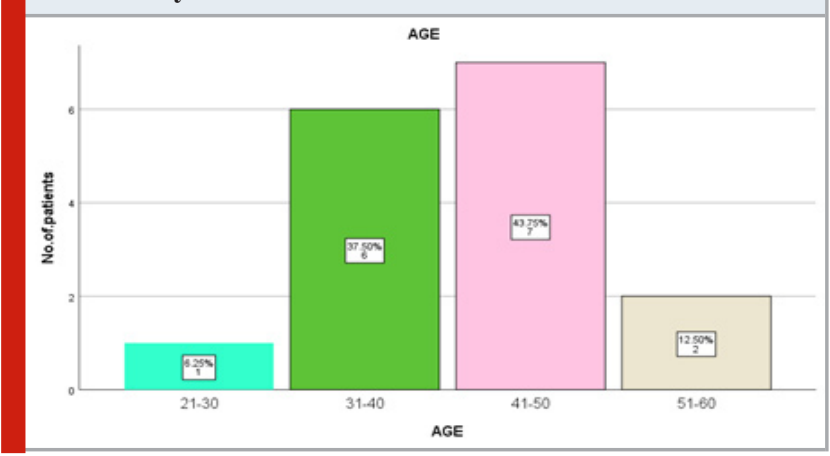

\section{RESULTS AND DISCUSSION}

The data was recorded from the oral oncology department patient records. Out of 57 carcinoma patients $16(28 \%)$ patients underwent the postoperative chemotherapy. The mean age of the patient's undergoing chemotherapy was 40-50 years ranging from 20 to 60 years of age (Figure $1)$. Based on the site of carcinoma - maxillary carcinoma accounts to 8 patients $(50 \%)$, mandibular carcinoma- 5 patients $(31.25 \%)$, buccal mucosa carcinoma- 3 patients 
$(18.75 \%)$ (Figure 2$)$. There was male predominance with 9 males (57\%) and 7 females (43\%) in this study (Figure $3)$. Chi-square test was done on association between gender and number of patients with carcinoma in different sites and found not statistically significant [chi square value- 0.2320 , $\mathrm{p}$ value- $0.314(\mathrm{p}>0.05)$ ] (Figure 4, Table 1$)$. Chi-square test was done to find the association between age and type of carcinoma and was found to be statistically not significant [chi square value-0.529, $\mathrm{p}$ value- $0.612(\mathrm{p}>0.05)$ ] (Figure 5, Table 2).

Figure 2: Figure shows prevalence of chemotherapy treatment offered to patients with different sites of carcinoma. $X$ axis represents various sites of carcinoma and $\mathrm{Y}$ axis denotes the number of patients treated with chemotherapy. Maxillary carcinoma (green)- 8 patients; Mandibular carcinoma(brown)- 5 patients; Buccal carcinoma (light orange)- 3 patients; maxillary carcinoma patients are treated majorly with chemotherapy. SPSS analysis was used.

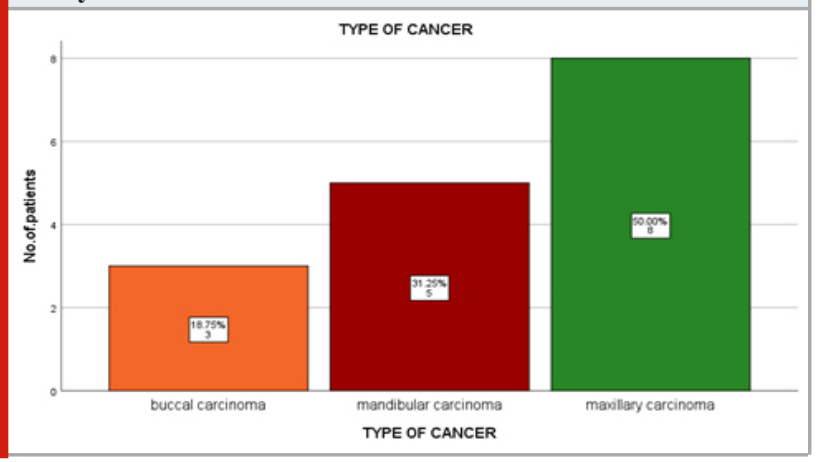

Figure 3: Figure denotes distribution of patients treated with chemotherapy across the gender. $X$ axis corresponds to the gender distribution and $\mathrm{Y}$ axis denotes the number of patients. Males(blue)-9 patients; Females(pink)- 7 patients. SPSS analysis was used and male predominance was found.

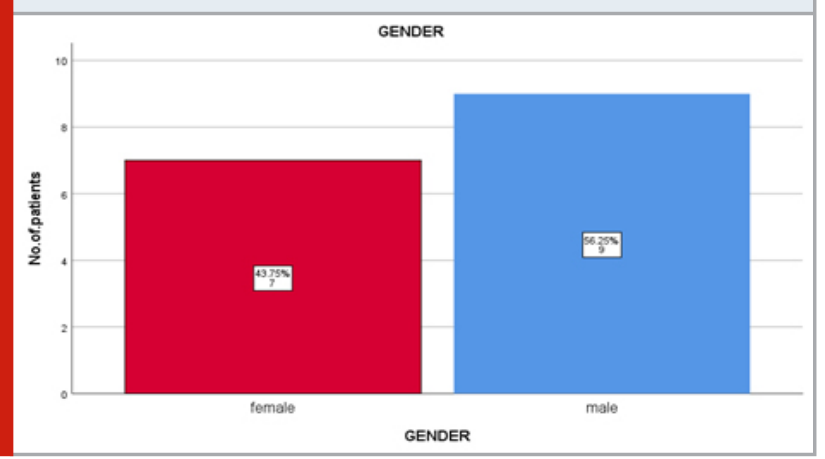

From this study we infer that $28 \%$ of patients in the sample were subjected to chemotherapy. Patients were predominantly in their fourth decade, with a male predominance. The association between the type of tumour treated post-operatively with age and gender is statistically not significant. This correlates with the study done by Pathak et al which showed a male predominance of $88 \%$. He concluded by stating that this is due to the high usage
Figure 4: Figure showing the association between the site of carcinoma and gender of the study population. $X$ axis corresponds to the gender affected and $\mathrm{Y}$ axis corresponds to the number of patients with carcinoma in different sites. Orange denotes buccal carcinoma; brown denotes mandibular carcinoma and green denotes maxillary carcinoma. Chi-square test was done on association between gender and number of patients with carcinoma in different sites and found not statistically significant [chi square value0.2320 , $p$ value- $0.314(p>0.05)]$.

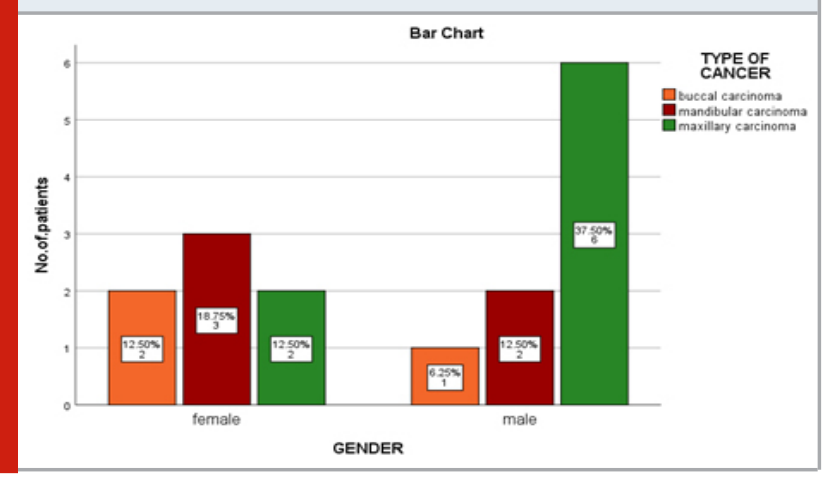

Table 1. Shows association between gender and type of carcinoma treated post operatively affected. There was no significance between the two parameters ( $p$ value $=$ 0.314).

\begin{tabular}{|l|c|c|c|}
\hline Chi-square tests & value & df & $\begin{array}{c}\text { Asymptotic } \\
\text { significance (2-sided) }\end{array}$ \\
\hline Pearson chi-square & 2.320 & 2 & 0.314 \\
\hline Likelihood ratio & 2.383 & 2 & 0.304 \\
\hline N.of valid cases & 16 & & \\
\hline
\end{tabular}

Figure 5- Figure showing the association between type of carcinoma and age of the study population. $X$ axis corresponds to the age group affected and $Y$ axis corresponds to the number of patients with carcinoma in different sites. Orange denotes buccal carcinoma; brown denotes mandibular carcinoma and green denotes maxillary carcinoma. Chi-square test was done to find the association between age and type of carcinoma and was found to be statistically not significant [chi square value- 0.529 , $p$ value$0.612(p>0.05)]$

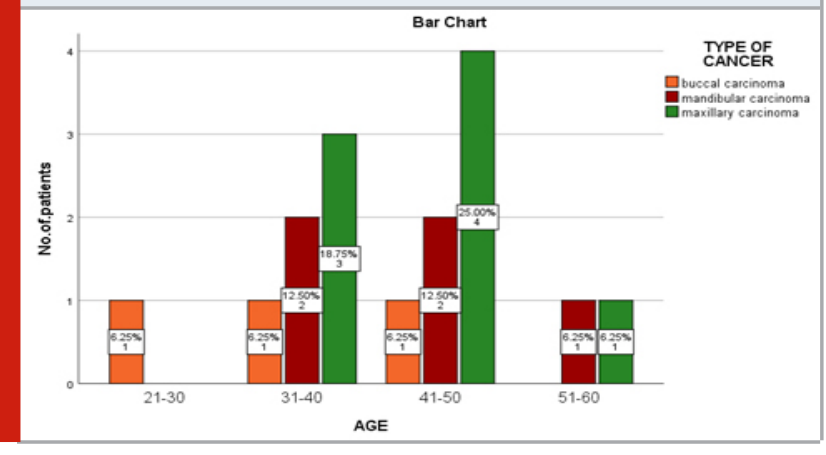


of the tobacco products among the male populations. The mean age group treated with chemotherapy was 41 - 50years though the study conducted by Pignon et.al, mentioned that chemotherapy treatment was given according to the TNM staging of cancer rather than the basis of age. In this sample majority patients were operated for maxillary oral squamous cell carcinoma (50\%) (Pathak et al., 2005; Pignon et al., 2009; Varghese et al., 2019; Muthukrishnan et al., 2020).

Stenson et al stated that adjuvant chemotherapy will be used after all known and the visible cancer was removed either surgically or with the help of radiation. High recurrence rate of certain carcinomatous lesions could be attributed to modified or defective cellular signaling pathways, altering physiological cell cycles to be pathological. Fabio et al, mentioned that $80-98 \%$ of the patients treated with chemotherapy postoperatively had highly recurrent OSCC lesions and only $2 \%$ that had low recurrence rate lesions. Chemotherapy was given where the oncologist considers there was a higher chance of recurrence (Okura et al., 1998; Cohen et al., 2014; Kumar, 2017b).

Table 2. Shows association between age group and type of carcinoma treated post operatively affected. There was no significance between the two parameters $(p$ value $=$ 0.529).

\begin{tabular}{|l|c|c|c|}
\hline Chi-square tests & value & df & $\begin{array}{c}\text { Asymptotic } \\
\text { significance (2-sided) }\end{array}$ \\
\hline Pearson chi-square & 5.117 & 6 & 0.529 \\
\hline Likelihood ratio & 4.476 & 6 & 0.612 \\
\hline N.of valid cases & 16 & & \\
\hline
\end{tabular}

Various combinations of drugs have been used in the treatment modality of oral squamous cell carcinoma. Multiple studies have been done to prove the efficiency of a regimen over another. Addition of docetaxel to cisplatin and 5-FU induction chemotherapy had been shown to improve survival compared with cisplatin and 5-FU, it was also associated with a significant increase in toxicity, including some treatment-related deaths(). Okura et al. in 1998 published a retrospective single institution review of Neoadjuvant Chemo Therapy (NACT) in patients with 141 operable oral cavity cancers. The post operative chemotherapy consisting of two cycles of cisplatin, vincristine, and peplomycin, with or without mitomycin $\mathrm{C}$ showed an overall response rate of $51.5 \%$, and there was a documented decrease in the rates of distant metastases though there was no decrease in overall or disease-free survival when all 141 patients were compared (Jesudasan et al., 2015; Jain et al., 2019; Mathew et al., 2020).

Patients undergoing surgical therapy are generally performed with mandibular or maxillary resection, which can cause significant facial deformity, dysphagia, pain, dyspnea, difficulty in airway maintenance reintubation challenges and reconstruction of post resective cervicofacial defects using local or distant vascular flaps. In addition to these problems, chemotherapy and radiotherapy can leave the healing mechanisms impaired leading to osteo-necrosis causing severe destruction of osseous and soft tissue structures which can be treated by following thorough debridement protocol 21. Hence it is crucial to plan for any dental treatment before planning for chemotherapy. If a patient undergoes extraction during chemotherapy treatment that can further lead to alveolar osteitis, osteomyelitis or even osteonecrosis. In order to prevent serious illness in chemotherapy planned patients who are generally immunocompromised due to post-surgical complications, an antibiotic prophylaxis is mandatory before any invasive dental procedure (Siegel, Naishadham and Jemal, 2012; Ma et al., 2013; Zhong et al., 2013; Cohen et al., 2014; Jesudasan et al., 2015; Jesudasan et al., 2015; Kumar and Sneha, 2016; Varghese et al., 2019; Muthukrishnan et al., 2020).

Evidence from literature proves significant proportion of patients exhibit response to neoadjuvant chemotherapy. These patients have been shown to have better locoregional control, disease-free survival. In addition, unresectable oral cavity cancers may be considered resectable after neoadjuvant chemotherapy. The identification of tumor response predictors may allow a more rational selection of therapeutic strategies, sparing unnecessary toxicities to patients who would not benefit from neoadjuvant chemotherapy. It could further lead to the development of new drug regimens to overcome primary resistance to postoperative chemotherapy.

No study falls short of drawbacks and our study's drawbacks are this is a single institution retrospective study within a shorter time span. Hence randomised clinical trials with long term follow ups using multiple combinations of drugs have to be conducted in a larger population to derive a more affirmative result. Our institution is passionate about high quality evidence based research and has excelled in various fields (Pc et al., 2018; Ramesh et al., 2018; Ezhilarasan et al., 2019; Ramadurai et al., 2019; Sridharan et al., 2019; Vijayashree, 2019; Mathew et al., 2020).

\section{CONCLUSION}

Within the limitations of this study, we can conclude that chemotherapy treatment was commonly undergone by men and patients in the 4th decade of life. Maxillary carcinoma patients underwent chemotherapy more commonly as compared to mandibular carcinoma patients or buccal carcinoma patients. Association between age and incidence of chemotherapy treatment, gender and incidence of chemotherapy treatment was found statistically not significant.

Conflict of Interest: There are no conflicts of interest

\section{ACKNOWLEDGEMENTS}

This study was supported by Saveetha institute of technical and medical sciences, Chennai. 


\section{REFERENCES}

Abhinav, R. P. et al. (2019). The Patterns and Etiology of Maxillofacial Trauma in South India. Annals of maxillofacial surgery, 9(1), pp. 114-117. doi: 10.4103/ ams.ams_233_18.

Christabel, A. et al. (2016). Comparison of pterygomaxillary dysjunction with tuberosity separation in isolated Le Fort I osteotomies: a prospective, multi-centre, triple-blind, randomized controlled trial. International Journal of Oral and Maxillofacial Surgery, pp. 180-185. doi: 10.1016/j. ijom.2015.07.021.

Cohen, E. E. W. et al. (2014). Phase III randomized trial of induction chemotherapy in patients with N2 or N3 locally advanced head and neck cancer. Journal of clinical oncology: official journal of the American Society of Clinical Oncology, 32(25), pp. 2735-2743. doi: 10.1200/ JCO.2013.54.6309.

Ezhilarasan, D., Apoorva, V. S. and Ashok Vardhan, N. (2019). Syzygium cumini extract induced reactive oxygen species-mediated apoptosis in human oral squamous carcinoma cells. Journal of oral pathology \& medicine: official publication of the International Association of Oral Pathologists and the American Academy of Oral Pathology, 48(2), pp. 115-121. doi: 10.1111/jop.12806. Gheena, S. and Ezhilarasan, D. (2019). Syringic acid triggers reactive oxygen species-mediated cytotoxicity in HepG2 cells. Human \& experimental toxicology, 38(6), pp. 694-702. doi: 10.1177/0960327119839173.

Jain V.S. et al. (2019). Evaluation of Three-Dimensional Changes in Pharyngeal Airway Following Isolated Lefort One Osteotomy for the Correction of Vertical Maxillary Excess: A Prospective Study. Journal of maxillofacial and oral surgery, 18(1), pp. 139-146. doi: 10.1007/s12663018-1113-4

Jesudasan, J. S., Abdul Wahab, P. U. and Muthu Sekhar, M. R. (2015). Effectiveness of $0.2 \%$ chlorhexidine gel and a eugenol-based paste on postoperative alveolar osteitis in patients having third molars extracted: a randomised controlled clinical trial. British Journal of Oral and Maxillofacial Surgery, pp. 826-830. doi: 10.1016/j. bjoms.2015.06.022.

Jose, J., Ajitha and Subbaiyan, H. (2020). Different treatment modalities followed by dental practitioners for Ellis class 2 fracture - A questionnaire-based survey. The open dentistry journal, 14(1), pp. 59-65. doi: $10.2174 / 1874210602014010059$.

Kademani, D. (2007). Oral Cancer. Mayo Clinic Proceedings, pp. 878-887. doi: 10.4065/82.7.878.

Kalavrezos, N. and Bhandari, R. (2010). Current trends and future perspectives in the surgical management of oral cancer. Oral Oncology, pp. 429-432. doi: 10.1016/j. oraloncology.2010.03.007.

Ke, Y. et al. (2019). Photosynthesized gold nanoparticles from Catharanthus roseus induces caspase-mediated apoptosis in cervical cancer cells (HeLa). Artificial cells, nanomedicine, and biotechnology, 47(1), pp. 1938-1946. doi: 10.1080/21691401.2019.1614017.
Krishnaswamy, H. et al. (2020). Investigation of air conditioning temperature variation by modifying the structure of passenger car using computational fluid dynamics', Thermal science, 24(1 Part B), pp. 495-498. doi: 10.2298/tsci190409397k.

Kumar, S. (2017a). Relationship Between Dental Anxiety and Pain Experience During Dental Extractions. Asian Journal of Pharmaceutical and Clinical Research, p. 458. doi: 10.22159/ajpcr. 2017.v10i3.16518.

Kumar, S. (2017b). The emerging role of botulinum toxin in the treatment of orofacial disorders: Literature update. Asian Journal of Pharmaceutical and Clinical Research, p. 21. doi: 10.22159/ajpcr. 2017.v10i9.16914.

Kumar, S. and Sneha, S. (2016). Knowledge and awareness regarding antibiotic prophylaxis for infective endocarditis among undergraduate dental students. Asian Journal of Pharmaceutical and Clinical Research, p. 154. doi: 10.22159/ajpcr. 2016.v9s2.13405.

Ma, J. et al. (2013). Induction chemotherapy in patients with resectable head and neck squamous cell carcinoma: a meta-analysis. World Journal of Surgical Oncology, p. 67. doi: 10.1186/1477-7819-11-67.

Malli Sureshbabu, N. et al. (2019). Concentrated Growth Factors as an Ingenious Biomaterial in Regeneration of Bony Defects after Periapical Surgery: A Report of Two Cases. Case reports in dentistry, 2019, p. 7046203. doi: $10.1155 / 2019 / 7046203$.

Mathew, M. G. et al. (2020). Evaluation of adhesion of Streptococcus mutans, plaque accumulation on zirconia and stainless steel crowns, and surrounding gingival inflammation in primary. Clinical oral investigations. Available at: https://link.springer.com/article/10.1007/ s00784-020-03204-9.

Mehta, M. et al. (2019). Oligonucleotide therapy: An emerging focus area for drug delivery in chronic inflammatory respiratory diseases. Chemico-biological interactions, 308, pp. 206-215. doi: 10.1016/j. cbi.2019.05.028.

Muthukrishnan, S. et al. (2020). Support vector machine for modelling and simulation of heat exchangers. Thermal science, 24(1 Part B), pp. 499-503. doi: 10.2298/ tsci190419398m.

Nagesh Rao, B. (2017). Learning Python. Available at: https://books.google.com/books/about/Learning_Python. html?hl=\&id=AUBptAEACAAJ.

Neville, B. W. and Day, T. A. (2002). Oral Cancer and Precancerous Lesions. CA: A Cancer Journal for Clinicians, pp. 195-215. doi: 10.3322/canjclin.52.4.195. Okura, M. et al. (1998). Induction chemotherapy is Associated with an increase in the incidence of locoregional recurrence in patients with carcinoma of the oral cavity. Cancer, pp. 804-815. doi: 10.1002/(sici)10970142(19980301)82:5<804::aid-cncr2>3.0.co;2-j.

Packiri, S. (2017). Management of Paediatric Oral Ranula: A Systematic Review. Journal of Clinical and Diagnostic Research. doi: 10.7860/jcdr/2017/28498.10622.

Packiri, S., Gurunathan, D. and Selvarasu, K. 
(2017). Management of Paediatric Oral Ranula: A Systematic Review. Journal of clinical and diagnostic research: JCDR, 11(9), pp. ZE06-ZE09. doi: 10.7860/ JCDR/2017/28498.10622.

Pathak, K. A. et al. (2005). Advanced squamous cell carcinoma of lower gingivobuccal complex: Patterns of spread and failure. Head \& Neck, pp. 597-602. doi: 10.1002/hed.20195.

Pc, J., Marimuthu, T. and Devadoss, P. (2018). Prevalence and measurement of anterior loop of the mandibular canal using CBCT: A cross sectional study. Clinical implant dentistry and related research. Available at: https:// europepmc.org/article/med/29624863.

Pignon, J.-P. et al. (2009). Meta-analysis of chemotherapy in head and neck cancer (MACH-NC): An update on 93 randomised trials and 17,346 patients. Radiotherapy and Oncology, pp. 4-14. doi: 10.1016/j.radonc.2009.04.014. Ramadurai, N. et al. (2019). Effectiveness of $\%$ Articaine as an anesthetic agent in children: randomized controlled trial. Clinical oral investigations, 23(9), pp. 3543-3550. doi: 10.1007/s00784-018-2775-5.

Ramesh, A. et al. (2018). Comparative estimation of sulfiredoxin levels between chronic periodontitis and healthy patients - A case-control study. Journal of periodontology, 89(10), pp. 1241-1248. doi: 10.1002/ JPER.17-0445.

Samuel, M. S. et al. (2019). Efficient removal of Chromium (VI) from aqueous solution using chitosan grafted graphene oxide (CS-GO) nanocomposite. International journal of biological macromolecules, 121, pp. 285-292. doi: 10.1016/j.ijbiomac.2018.09.170.

Samuel, S. R., Acharya, S. and Rao, J. C. (2020). School Interventions-based Prevention of Early-Childhood Caries among 3-5-year-old children from very low socioeconomic status: Two-year randomized trial. Journal of public health dentistry, 80(1), pp. 51-60. doi: 10.1111/jphd.12348.

Sathish, T. and Karthick, S. (2020). Wear behaviour analysis on aluminium alloy 7050 with reinforced $\mathrm{SiC}$ through taguchi approach. Journal of Japan Research Institute for Advanced Copper-Base Materials and Technologies, 9(3), pp. 3481-3487. doi: 10.1016/j.jmrt.2020.01.085.

Sharma, P. et al. (2019). Emerging trends in the novel drug delivery approaches for the treatment of lung cancer.
Chemico-biological interactions, 309, p. 108720. doi: 10.1016/j.cbi.2019.06.033.

Siegel, R., Naishadham, D. and Jemal, A. (2012). Cancer statistics, 2012. CA: a cancer journal for clinicians, 62(1), pp. 10-29. doi: 10.3322/caac.20138.

Sridharan, G. et al. (2019). Evaluation of salivary metabolomics in oral leukoplakia and oral squamous cell carcinoma. Journal of oral pathology \& medicine: official publication of the International Association of Oral Pathologists and the American Academy of Oral Pathology, 48(4), pp. 299-306. doi: 10.1111/jop.12835.

Varghese, S. S., Ramesh, A. and Veeraiyan, D. N. (2019). Blended Module-Based Teaching in Biostatistics and Research Methodology: A Retrospective Study with Postgraduate Dental Students. Journal of dental education, 83(4), pp. 445-450. doi: 10.21815/JDE.019.054.

Venu, H., Raju, V. D. and Subramani, L. (2019). Combined effect of influence of nano additives, combustion chamber geometry and injection timing in a DI diesel engine fuelled with ternary (diesel-biodiesel-ethanol) blends. Energy, 174, pp. 386-406. doi: 10.1016/j.energy.2019.02.163.

Venu, H., Subramani, L. and Raju, V. D. (2019). Emission reduction in a DI diesel engine using exhaust gas recirculation (EGR) of palm biodiesel blended with $\mathrm{TiO} 2$ nano additives. Renewable Energy, 140, pp. 245-263. doi: 10.1016/j.renene.2019.03.078.

Vignesh, R. et al. (2019). Management of Complicated Crown-Root Fracture by Extra-Oral Fragment Reattachment and Intentional Reimplantation with 2 Years Review. Contemporary clinical dentistry, 10(2), pp. 397-401. doi: 10.4103/ccd.ccd_671_18.

Vijayashree P. J. (2019). In silico validation of the non-antibiotic drugs acetaminophen and ibuprofen as antibacterial agents against red complex pathogens', Journal of periodontology, 90(12), pp. 1441-1448. doi: 10.1002/JPER.18-0673.

Zhong, L.-P. et al. (2013). Randomized phase III trial of induction chemotherapy with docetaxel, cisplatin, and fluorouracil followed by surgery versus up-front surgery in locally advanced resectable oral squamous cell carcinoma. Journal of clinical oncology: official journal of the American Society of Clinical Oncology, 31(6), pp. 744-751. doi: 10.1200/JCO.2012.43.8820. 